\title{
Hip fractures and characteristics of living area: a fine-scale spatial analysis in France
}

Rozenn Héquette-Ruz ${ }^{1}$, Jean-Baptiste Beuscart ${ }^{1-2, *}$, Grégoire Ficheur ${ }^{2-3}$, Emmanuel Chazard ${ }^{2-3}$, Elodie Guillaume ${ }^{4}$, Julien Paccou ${ }^{5}$, François Puisieux ${ }^{1,2}$, Michaël Genin ${ }^{2}$.

${ }^{1}$ CHU Lille, Geriatrics department, F-59000 Lille, France

${ }^{2}$ Univ. Lille, CHU Lille, EA 2694 - Evaluation des technologies de santé et des pratiques médicales, F-59000 Lille, France

${ }^{3}$ CHU Lille, Public Health Department, F-59000 Lille, France

${ }^{4}$ U1086 INSERM, Université Caen Normandie - UFR Santé

${ }^{5}$ Univ. Lille, CHU Lille, MABLab UR 4490, department of rheumatology, 59000 Lille, France

\section{*Corresponding author's address:}

Jean-Baptiste Beuscart, CERIM, EA 2694, Faculté de Médecine - Pôle Recherche, 1, place Verdun, F - 59045 Lille Cedex, France.

Tel: +33 32062 6969; Fax: +33 320626881

E mail: jean-baptiste.beuscart@univ-lille.fr

\section{Conflict of interest statement}

Rozenn Héquette-Ruz, Jean-Baptiste Beuscart, Grégoire Ficheur, Emmanuel Chazard, Elodie Guillaume, Julien Paccou, François Puisieux, and Michaël Genin declare that they have no conflict of interest. 


\section{ABSTRACT}

Summary: We investigated the association between hip fracture incidence and living area characteristics in France. The spatial distribution of hip fractures incidence was heterogeneous and there was a significant relationship between social deprivation, urbanization, health access and hip fractures risk.

Purpose: Several studies have shown great disparities in spatial repartition of hip fractures (HF). The aim of the study was to analyze the association between HF incidence and characteristics of the living area.

Methods: All patients aged 50 or older, living in France, who were hospitalized for HF between 2012 and 2014 were included, using the French national hospital discharge database. Standardized Incidence Ratio (SIR) were calculated for each spatial unit and adjusted on age and sex. An ecological regression was performed to analyze the association between HF standardized incidence and ecological variables. We adjusted the model for neighborhood spatial structure. We used three variables to characterize the living areas: a deprivation index (French-EDI); healthcare access (French standardized index); land use (percentage of artificialized surfaces).

Results: 236,328 HF were recorded in the French hospital national database, leading to an annual HF incidence of 333/100,000. The spatial analysis revealed geographical variations of HF incidence with SIR varying from 0.67 [0.52; 0.85$]$ to 1.45 [1.23; 1.70$]$. There was a significant association between HF incidence rates and: (1) French-EDI index (trend $p=0.0023$ ); (2) general practitioner and nurse accessibility (trend $\mathrm{p}=0.0232$ and $\mathrm{p}=0.0129$, respectively); (3) percentage of artificialized surfaces $(\mathrm{p}<0.0001)$.

Conclusion: the characteristics of the living area are associated with significant differences in the risk of hip fracture of older people.

Keywords: hip fracture, spatial regression, elderly, ecological factors 


\section{INTRODUCTION}

In Europe, hip fractures (HF) are the second most common osteoporotic fractures after vertebral fractures (1). In the United States, their annual incidence rate was 195/100,000 in 2012 (2). These fractures mostly occur in elderly subjects following a low kinetic trauma related to a fall from their own height. HF represent a major public health issue for older adults as they are associated with unplanned use of care, loss of functional independence, higher risk of institutionalization and death (3-5). Their annual cost in Europe was estimated at 20*109 euros in 2010 (1).

There are spatial disparities in the incidence of HF, both at continental and national levels $(2,6)$. Most national-level studies use large spatial units (regions or provinces), which limits the accuracy of the spatial description of HF incidence $(7,8)$. Although the main risk factors for HF are well identified, the cause of these variations is not known. The spatial heterogeneity of distribution suggests that environmental and socio-economic factors are involved in the occurrence of HF. Among these factors, social deprivation has been analyzed at both individual and ecological levels (9-12), urbanization was studied at the individual level (13), and health access was not investigated.

The objective of this study is to analyze the spatial distribution of HF incidence on a small scale in metropolitan France and to study the association between HF incidence and relevant characteristics of the living environment (social deprivation, land use and healthcare disparities).

\section{METHODS}

\section{$\underline{\text { Study area }}$}

This study was conducted in metropolitan France totaling 64 million inhabitants at the time of the 2013 population census conducted by the French National Institute of Statistics and Economic Studies (INSEE) (14). Its surface area is 543,965 km², with an average of 118 inhabitants per $\mathrm{km}^{2}$. The French population dispersal on the territory is extremely heterogeneous: $10 \%$ of the population lives on $50 \%$ of the territory (21 inhabitants $/ \mathrm{km}^{2}$ ), while $40 \%$ of the population is concentrated on $1 \%$ of the 
territory, with densities exceeding 20,000 inhabitants $/ \mathrm{km}^{2}$ (in Paris). A hybrid spatial unit, described in our previous work, has been used dividing the French area in 5,610 analysis spatial units (15). These 5610 analysis spatial units have a median surface area [interquartile range] of $70.0[21.6 ; 147.6] \mathrm{km}^{2}$, and a median population of 6,300 [3,500; 11,800] inhabitants.

\section{Ethics and approvals}

This observational study consisted of a secondary use of nationwide anonymous data. It was performed within the frame of a specific French national regulation. This study was approved by the CNIL (the French government's office for data protection), authorization number 1928270. No IRB approval was necessary.

\section{Data source}

HF cases were issued from the French nationwide hospital discharge database which covers all nonprofit and for-profit healthcare facilities in France (16). For each inpatient stay, the standardized discharge record notably included: socio-demographic data (age, gender, anonymized ZIP code), primary and associated discharge diagnostic codes encoded in ICD-10 (WHO's International Classification of Diseases, 10th revision), and diagnostic and therapeutic procedures encoded in CCAM, a French terminology.

\section{Data extraction}

A first selection of patients was carried out over the 2012-2014 period. The inclusion criteria were: 1) age 50 or over; 2) place of residence in metropolitan France (excluding ultramarine areas); 3) diagnosis of hip fracture according to the ICD-10 classification (codes: S72.0, S72.1, S72.2, S72.9). The exclusion criteria were hip fracture on prosthesis (M96.6), mechanical or infectious complications of prosthesis (T84.*), arthritis with pyogenic bacteria (M00.*), infectious arthritis (M01.*), and multiple fractures (T029).

Among the eligible patients, a second selection was made by including data from the 2007-2011 period in order to exclude patients at risk of pathological fracture in 2012-2014. Patients who had at 
least one hospitalization with one of the following codes during the period 2007-2011 were secondarily excluded: malignant tumor of the long bones of the lower limb (C40.2), malignant tumor of the bones and joint cartilage of a limb (C40.9), secondary malignant tumor of bone and bone marrow (C79.5), multiple myeloma (C90.0), pathological fracture - multiple site (M884.0), pathological fracture - pelvic region and thigh (M884.5), pathological fracture - other locations (M884.8), pathological fracture - site unspecified (M884.9). Stays were excluded if one of the above codes was present, either for the current stay (between 2012 and 2014) or as an antecedent (between 2007 and 2011). The ICD-10 codes used for patient inclusion and exclusion are based on a synthesis of several similar studies recently published on the epidemiology of $\operatorname{HF}(12,17,18)$.

\section{$\underline{\text { HF incidence rate }}$}

The HF incidence rate was then calculated for each of the 5610 analysis spatial units. The population data used for the incidence calculations came from the 2013 INSEE census. The data were stratified by sex and five-year age group.

\section{Ecological variables}

The ecological variables were selected from the aggregated indicators, validated and available at the spatial unit of open data analysis. The indicators represented social disadvantage, healthcare disparities and land use.

Deprivation index. The social disadvantage data were obtained using the French version of the European Deprivation Index $(19,20)$. Higher is the French-EDI, more important is the deprivation in the spatial unit. The EDI is an ecological index of social deprivation constructed on a very fine scale. It is a weighted combination of census variables: home ownership, home overcrowding, presence of bath or shower, car ownership, single-parent families, education level, employment and foreign nationality.

Healthcare disparities. Healthcare accessibility was measured using the Localized Potential Accessibility Index (LPA) proposed by Barlet et al. (21). For each spatial unit, this indicator represents the accessibility to an average number of consultations of one practitioner per inhabitant. 
This indicator considers, among other things, the distance by road between a patient and his or her healthcare professional, the age structure of the population and the number of annual consultations per healthcare professional. The LPA was measured for general practitioners (GP accessibility) and for private nurses (Nurse accessibility).

Land use. We considered for each analysis spatial unit the percentage of artificialized surfaces, corresponding to level 1 (artificial surfaces) of the CORINE Land Cover database (22). This percentage included urban fabrics, industrial, commercial and transport units, mine, dump and construction sites and artificial non-agricultural vegetated areas.

\section{$\underline{\text { Statistical analyses }}$}

Descriptive analysis. Quantitative variables were described by means (and standard deviations, SD) in the case of normal distribution, and by their median (and interquartile ranges) otherwise. The normality of the variables was assessed using histogram, normal probability plot and the Shapiro-Wilk test. The qualitative variables were described by their frequencies (and percentages).

Standardized Incidence Ratios (SIR). The spatial distribution of HF incidence was assessed using Standardized Incidence Ratios (SIR) computed for each spatial unit. For a spatial unit, the SIR is defined as the ratio between the observed number of HF and the expected number of HF calculated by using an indirect standardization on age and gender which are well-known confounding factors of HF incidence (23). 95\% CI denote the 95\% confidence intervals.

Spatial heterogeneity and spatial autocorrelation evaluation. The existence of spatial variation of HF incidence between spatial units has been tested by the Potthoff-Whittinghill test (24). The presence of spatial autocorrelation among the spatial units was quantified using the Moran's index (25) (a value greater than 0 denotes the presence of autocorrelation) and tested using Moran's test (26).

Smoothed SIR and ecological regression. In order to take into account the SIR instability related to low frequencies and the spatial autocorrelation, the SIRs were smoothed using the Bayesian Poisson regression model proposed by Besag et al. (27). In order to analyze the association between HF ageand-gender standardized incidence and ecological variables, we used an extension of the previous 
model, namely ecological regression, consisting in the inclusion of ecological covariates as fixed effects in the model. All ecological covariates were included in this multivariate model. Each ecological covariate was divided into quartiles. For each level of the ecological covariates, a relative risk of HF incidence and its Bayesian credibility interval (BCI) were computed. For each categorical ecological covariate, a trend test was performed. As HF incidence was different between men and women, we performed a stratified analysis according to gender. A sensitivity analysis was carried out to assess the independence of the three ecological covariates (deprivation index, healthcare access and land use) by adding and evaluating interaction terms in the previously described Bayesian ecological regression model.

The Potthoff-Whittinghill and Moran's methods, SIR's smoothing and ecological regressions were carried out using the R software v. 3.4.3 (packages: DCluster, R-INLA) (28). Maps were produced using the QGIS 2.18 software (29). All statistical analyses were considered significant at 0.05 type 1 error.

\section{RESULTS}

\section{Crude HF incidence in metropolitan France}

In 2013, the total population of people aged 50 or over residing in metropolitan France was 23,624,484, including 12,894,655 women (54.6\%). Between 2012 and 2014, 236,328 incident cases of hip fractures were recorded in the French national hospital discharge database (74.3\% female and 25.7\% male). Data extraction and selection process are detailed in Figure 1. The median age of occurrence was $82[72 ; 88]$ years in men and $85[80 ; 90]$ years in women. The average annual incidence of HF was therefore 333/100,000 (95\% CI [332.1; 334.8]). Details of the stratified incidences by age and sex are provided in Table 1 . The incidence was higher among women in all age groups. Moreover, the annual incidence increased sharply with age, rising from 27/100,000 among women aged 50-54 to 2043/100,000 between 85 and 89 years old.

\section{Geographical variations of HF incidence}


There was a significant spatial heterogeneity of HF incidence rates (Potthoff-Whittinghill test $\mathrm{p}=0.001$ ) with evidence for spatial autocorrelation between the different spatial units (Moran I statistics $=0.10 ; \mathrm{p}=0.001)$. Therefore, a Bayesian hierarchical Poisson model for smoothing Standardized Incidence Ratios (SIRs) was used for the analyses. The age-and-gender- smoothed SIRs varied from 0.67 [0.52; 0.85$]$ to 1.45 [1.23; 1.70]. The geographical distribution of smoothed SIRs is presented in Figure 2.

\section{$\underline{\text { Association with ecological variables }}$}

The results of the ecological regression analysis between HF incidence rates and ecological variables are shown in Figure 3. No interaction term was significant in the sensitivity analysis, suggesting that the three ecological covariates were independent. The results are detailed in supplementary data 1.

Regarding social disadvantage, there was a significant association (trend $\mathrm{p}=0.0023$ ) between HF incidence rates and French-EDI index: compared to the first quartile of French-EDI (Q1), the relative risk of HF was 1.02[1.00; 1.03] for Q2, 1.03[1.01; 1.05] for Q3 and 1.03[1.01; 1.05] for Q4.

Regarding healthcare disparities, a significant association (trend $\mathrm{p}=0.0232$ ) was observed between HF incidence rates and GP accessibility: compared to the highest values of GP accessibility (Q4), the relative risk of HF was 1.01 [0.99; 1.03] for Q3, 1.01 [0.99; 1.03] for Q2 and 1.02 [1.00; 1.04] for Q1. A significant association was also observed (trend $\mathrm{p}=0.0129$ ) between HF incidence rates and Nurse accessibility: compared to the highest Nurse accessibility values (Q4), the relative risk of HF was 1.01 [0.99;1.03] for Q3, 1.01 [0.99; 1.03] for Q2 and 1.02 [1.00;1.05] for Q1.

Regarding land use, a significant association $(\mathrm{p}<0.0001)$ was observed between HF incidence rates and the percentage of artificialized surfaces: compared to the highest percentages (Q4), the relative risk of HF was 1.00 [0.99; 1.02] for Q3, 1.04 [1.02; 1.06] for Q2 and 1.04 [1.02; 1.07] for Q1.

\section{Difference between men and women}

The results of the analysis stratified according to gender is provided in Table 2. The association between Fench-EDI and HF incidence rates was no longer significant in women (trend, $P=0.16$ ) but 
remained significant in men (trend, $P<0.0001$ ). Relative risks for all quartiles of French-EDI were all higher in men than in the whole population. Similarly, the association between nurse accessibility and HF incidence rates was no longer significant in women (trend, $\mathrm{P}=0.53$ ) but remained significant in men (trend, $\mathrm{P}<.01$ ).

\section{DISCUSSION}

In our study, the average annual incidence of HF in France between 2012 and 2014 was 333/100,000, and most of these fractures occurred in people over 75 years of age. The spatial distribution of HF incidence was heterogeneous in France. There was a weak significant relationship between the characteristics of the elderly person's living area and HF risk.

In Europe, HF incidence varies significantly, from 132/100,000 in Poland to 439/100,000 in Denmark $(30,31)$. In the USA, the annual incidence of HF is estimated at 195/100,000 among people over 50 years of age (32). In our study, the estimated annual HF incidence rate is $333 / 100,000$ and is consistent with Western countries' data. The spatial heterogeneity of HF incidence has been observed in several countries: in the USA at the provincial level, in the UK at the regional level, in Germany at the Länder level, and in Portugal at a small-scale level (municipalities) (18,33-35). In France, heterogeneity has also been highlighted by a very large scale (36) and we confirm these results with a fine-scale spatial analysis.

In our study, an ecological regression showed an association between HF incidence and social deprivation. This association is known and demonstrated at the individual level in several prospective and retrospective cohort studies (Spain, Switzerland, UK) $(10,11,37)$. This association was also highlighted at the ecological level in a study carried out in Portugal by Oliveira et al. (38). Our study also finds an association with healthcare accessibility and the percentage of artificialized surface of the living area. This result, derived from an ecological regression, seems interesting since this information is difficult to collect in a detailed and standardized way at the individual level. The search for an association between the risk of HF and urbanization of the living area is often based on a qualitative variable (rural/urban). This measure is coarser than the use of the standardized European land use 
measure. This may explain conflicting results regarding the comparison of HF incidence between rural and urban populations $(13,34)$. Access to primary care has not been studied at the individual level as a risk factor for HF. Studies on healthcare disparities related to HF described access to surgery and rehabilitation $(39,40)$.

High prevalence of adverse lifestyle habits (e.g. smoking, excessive alcohol intake...) and poorer dietary quality (e.g. protein intake, calcium and vitamin D intake...) are associated with lower socioeconomic status. Given documented adverse effects on bone health, these habits are likely to contribute to socioeconomic variation in our study. A similar finding of greater association between social deprivation and HF risk in men than women has been previously documented $(33,41,42)$. Possible explanations include the different magnitude of lifestyle habits between men and women, greater frequency of traumatic events in men than women, undertreatment of osteoporosis in men $(43,44)$ and greater frequency of multimorbidity in men than women $(45)$ in low compared with high socioeconomic status groups.

The strengths of our study are: the number of subjects included ensuring significant statistical power at the national level, the fine-scale spatial analysis reducing ecological bias, the use of a robust statistical method to adjust on spatial autocorrelation to describe the links between incidence and ecological variables, the use of validated and standardized ecological variables.

However, some limitations should be highlighted. First, ecological variables are measured at the scale of the living territory and not at the individual level. As a result, the associations found in this study cannot be considered at the individual scale. In addition, the coding of diagnoses in the French national hospital discharge database can lead to errors with a risk of not including some patients admitted for HF. However, these errors are probably minimal since the financing of hospital stays depends on the coding in the French nationwide hospital discharge database. Another limitation is that the level of trauma and several important confounders that may affect the risk of HF at the individual level - including falls, drugs, comorbidities (e.g. Charlson comorbidities index...), physical activity, body mass index, smoking, alcohol consumption, and use of vitamin D and calcium supplements - 
were not assessed. In addition, we had no information on bone mineral density and drugs used to treat osteoporosis (e.g. bisphosphonates, hormone replacement therapy...).

In conclusion, the characteristics of the living area are associated with the risk of HF among the elderly living there. Future epidemiological studies analysing individual HF risk factors could use information on the living environment via open access data.

\section{References}

1. Hernlund E, Svedbom A, Ivergård M, Compston J, Cooper C, Stenmark J, et al. Osteoporosis in the European Union: medical management, epidemiology and economic burden. A report prepared in collaboration with the International Osteoporosis Foundation (IOF) and the European Federation of Pharmaceutical Industry Associations (EFPIA). Arch Osteoporos. 2013;8:136.

2. Kanis JA, Odén A, McCloskey EV, Johansson H, Wahl DA, Cooper C, et al. A systematic review of hip fracture incidence and probability of fracture worldwide. Osteoporos Int J Establ Result Coop Eur Found Osteoporos Natl Osteoporos Found USA. sept 2012;23(9):2239-56.

3. Johnell O, Kanis JA. An estimate of the worldwide prevalence, mortality and disability associated with hip fracture. Osteoporos Int J Establ Result Coop Eur Found Osteoporos Natl Osteoporos Found USA. nov 2004;15(11):897-902.

4. Dyer SM, Crotty M, Fairhall N, Magaziner J, Beaupre LA, Cameron ID, et al. A critical review of the long-term disability outcomes following hip fracture. BMC Geriatr. 2 sept 2016;16:158.

5. Morin S, Lix LM, Azimaee M, Metge C, Majumdar SR, Leslie WD. Institutionalization following incident non-traumatic fractures in communitydwelling men and women. Osteoporos Int J Establ Result Coop Eur Found Osteoporos Natl Osteoporos Found USA. sept 2012;23(9):2381-6.

6. Cheng SY, Levy AR, Lefaivre KA, Guy P, Kuramoto L, Sobolev B. Geographic trends in incidence of hip fractures: a comprehensive literature review. Osteoporos Int J Establ Result Coop Eur Found Osteoporos Natl Osteoporos Found USA. oct 2011;22(10):2575-86.

7. Orimo H, Yaegashi $Y$, Hosoi T, Fukushima $Y$, Onoda $T$, Hashimoto $T$, et al. Hip fracture incidence in Japan: Estimates of new patients in 2012 and 25-year trends. Osteoporos Int J Establ Result Coop Eur Found Osteoporos Natl Osteoporos Found USA. mai 2016;27(5):1777-84.

8. Klop C, van Staa TP, Cooper C, Harvey NC, de Vries F. The epidemiology of mortality after fracture in England: variation by age, sex, time, geographic location, and ethnicity. Osteoporos Int J Establ Result Coop Eur Found Osteoporos Natl Osteoporos Found USA. 2017;28(1):161-8.

9. Brennan SL, Holloway KL, Williams LJ, Kotowicz MA, Bucki-Smith G, Moloney DJ, et al. The social gradient of fractures at any skeletal site in men and 
women: data from the Geelong Osteoporosis Study Fracture Grid. Osteoporos Int J Establ Result Coop Eur Found Osteoporos Natl Osteoporos Found USA. avr 2015;26(4):1351-9.

10. Guilley E, Herrmann F, Rapin C-H, Hoffmeyer P, Rizzoli R, Chevalley T. Socioeconomic and living conditions are determinants of hip fracture incidence and age occurrence among community-dwelling elderly. Osteoporos Int J Establ Result Coop Eur Found Osteoporos Natl Osteoporos Found USA. févr 2011;22(2):647-53.

11. Reyes C, García-Gil M, Elorza JM, Fina-Avilés F, Mendez-Boo L, Hermosilla E, et al. Socioeconomic status and its association with the risk of developing hip fractures: a region-wide ecological study. Bone. avr 2015;73:127-31.

12. Petit M-P, Bryère J, Maravic M, Pallaro F, Marcelli C. Hip fracture incidence and social deprivation: results from a French ecological study. Osteoporos Int J Establ Result Coop Eur Found Osteoporos Natl Osteoporos Found USA. juill 2017;28(7):2045-51.

13. Brennan SL, Pasco JA, Urquhart DM, Oldenburg B, Hanna FS, Wluka AE. The association between urban or rural locality and hip fracture in communitybased adults: a systematic review. J Epidemiol Community Health. août 2010;64(8):656-65.

14. Insee - Institut national de la statistique et des études économiques [Internet]. [cité 17 août 2019]. Disponible sur: https://www.insee.fr/fr/accueil

15. Ghenassia A, Beuscart JB, Ficheur G, Occelli F, Babykina E, Chazard E, et al. A generic method for improving the spatial interoperability of medical and ecological databases. Int J Health Geogr. 03 2017;16(1):36.

16. ATIH : Agence technique de l'information sur l'hospitalisation [Internet]. [cité 17 août 2019]. Disponible sur: https://www.atih.sante.fr/

17. Wang J, Wang Y, Liu W-D, Wang F, Yin Z-S. Hip fractures in Hefei, China: the Hefei osteoporosis project. J Bone Miner Metab. mars 2014;32(2):206-14.

18. Defèr A, Schober H-C, Möhrke W, Abendroth K, Hofbauer LC, Task Group for Treatment Research at German Society of Osteology, Federal Association of German Osteologists (Bundesverband der Osteologen Deutschland e.V.), et al. Are there still east-to-west differences in the incidence of hip fractures in Germany? Arch Osteoporos. 2014;9:195.

19. Guillaume E, Pornet C, Dejardin O, Launay L, Lillini R, Vercelli M, et al. Development of a cross-cultural deprivation index in five European countries. J Epidemiol Community Health. mai 2016;70(5):493-9.

20. Pornet C, Delpierre C, Dejardin O, Grosclaude P, Launay L, Guittet L, et al. Construction of an adaptable European transnational ecological deprivation index: the French version. J Epidemiol Community Health. nov 2012;66(11):982-9.

21. Barlet $M$, Coldefy $M$, Collin C, Lucas-Gabrielli V. L'accessibilité aux médecins généralistes libéraux : plus faible en milieu rural. Pour. 2012; ${ }^{\circ}$ 214(2):29-40. 
22. CORINE land cover technical guide - Addendum 2000 [Internet]. European Environment Agency. [cité 17 août 2019]. Disponible sur:

https://www.eea.europa.eu/publications/tech40add

23. NIH Consensus Development Panel on Osteoporosis Prevention, Diagnosis, and Therapy. Osteoporosis prevention, diagnosis, and therapy. JAMA. 14 févr 2001;285(6):785-95.

24. Potthoff RF, Whittinghill M. Testing for homogeneity. I. The binomial and multinomial distributions. Biometrika. juin 1966;53(1):167-82.

25. Moran PAP. The Interpretation of Statistical Maps. J R Stat Soc Ser B Methodol. 1948;10(2):243-51.

26. Cho DG. Spatial Processes: Models and Applications by A.D. Cliff and J.K. Ord. 16 by 24 em, 266 pages, maps, diags., index and bibliography. london: Pion Limited, 1981. (ISBN 08-85086-081-4). £20.50. Cartography. 1 mars 1983;13(1):59-60.

27. Besag J, York J, Mollié A. Bayesian image restoration, with two applications in spatial statistics. 1991;43(1):1-20.

28. R: a language and environment for statistical computing [Internet]. [cité 17 août 2019]. Disponible sur: https://www.gbif.org/fr/tool/81287/r-a-languageand-environment-for-statistical-computing

29. Bienvenue sur le projet QGIS ! [Internet]. [cité 17 août 2019]. Disponible sur: https://qgis.org/fr/site/

30. Czerwinski E, Kanis JA, Trybulec B, Johansson H, Borowy P, Osieleniec J. The incidence and risk of hip fracture in Poland. Osteoporos Int J Establ Result Coop Eur Found Osteoporos Natl Osteoporos Found USA. août 2009;20(8):1363-7.

31. Abrahamsen B, Vestergaard P. Declining incidence of hip fractures and the extent of use of anti-osteoporotic therapy in Denmark 1997-2006. Osteoporos Int J Establ Result Coop Eur Found Osteoporos Natl Osteoporos Found USA. mars 2010;21(3):373-80.

32. Ettinger B, Black DM, Dawson-Hughes B, Pressman AR, Melton LJ. Updated fracture incidence rates for the US version of FRAX. Osteoporos Int J Establ Result Coop Eur Found Osteoporos Natl Osteoporos Found USA. janv 2010;21(1):25-33.

33. Curtis EM, van der Velde R, Moon RJ, van den Bergh JPW, Geusens P, de Vries F, et al. Epidemiology of fractures in the United Kingdom 1988-2012: Variation with age, sex, geography, ethnicity and socioeconomic status. Bone. juin 2016;87:19-26.

34. de Pina MF, Alves SM, Barbosa M, Barros H. Hip fractures cluster in space: an epidemiological analysis in Portugal. Osteoporos Int J Establ Result Coop Eur Found Osteoporos Natl Osteoporos Found USA. déc 2008;19(12):1797-804. 
35. Banerjee G, Zullo AR, Berry SD, Lee Y, McConeghy K, Kiel DP, et al. Geographic Variation in Hip Fracture Among United States Long-Stay Nursing Home Residents. J Am Med Dir Assoc. 01 2016;17(9):865.e1-3.

36. Barbier S, Ecochard R, Schott A-M, Colin C, Delmas PD, Jaglal SB, et al. Geographical variations in hip fracture risk for women: strong effects hidden in standardised ratios. Osteoporos Int J Establ Result Coop Eur Found Osteoporos Natl Osteoporos Found USA. mars 2009;20(3):371-7.

37. Quah C, Boulton C, Moran C. The influence of socioeconomic status on the incidence, outcome and mortality of fractures of the hip. J Bone Joint Surg Br. juin 2011;93(6):801-5.

38. Oliveira CM, Economou T, Bailey T, Mendonça D, Pina MF. The interactions between municipal socioeconomic status and age on hip fracture risk. Osteoporos Int J Establ Result Coop Eur Found Osteoporos Natl Osteoporos Found USA. févr 2015;26(2):489-98.

39. Dy CJ, Lane JM, Pan TJ, Parks ML, Lyman S. Racial and Socioeconomic Disparities in Hip Fracture Care. J Bone Joint Surg Am. 18 mai 2016;98(10):858-65.

40. Freburger JK, Holmes GM, Ku L-JE. Postacute rehabilitation care for hip fracture: who gets the most care? J Am Geriatr Soc. oct 2012;60(10):1929-35.

41. Bhimjiyani A, Neuburger J, Jones T, Ben-Shlomo Y, Gregson CL. The effect of social deprivation on hip fracture incidence in England has not changed over 14 years: an analysis of the English Hospital Episodes Statistics (20012015). Osteoporos Int J Establ Result Coop Eur Found Osteoporos Natl Osteoporos Found USA. 2018;29(1):115-24.

42. Court-Brown CM, Aitken SA, Ralston SH, McQueen MM. The relationship of fall-related fractures to social deprivation. Osteoporos Int J Establ Result Coop Eur Found Osteoporos Natl Osteoporos Found USA. avr 2011;22(4):1211-8.

43. Curtis JR, McClure LA, Delzell E, Howard VJ, Orwoll E, Saag KG, et al. Population-based fracture risk assessment and osteoporosis treatment disparities by race and gender. J Gen Intern Med. août 2009;24(8):956-62.

44. Kiebzak GM, Beinart GA, Perser K, Ambrose CG, Siff SJ, Heggeness MH. Undertreatment of osteoporosis in men with hip fracture. Arch Intern Med. 28 oct 2002;162(19):2217-22.

45. Cauley JA, Cawthon PM, Peters KE, Cummings SR, Ensrud KE, Bauer DC, et al. Risk Factors for Hip Fracture in Older Men: The Osteoporotic Fractures in Men Study (MrOS). J Bone Miner Res Off J Am Soc Bone Miner Res. 2016;31(10):1810-9. 
Table 1: Total number of hip fractures, French population (2013 national census) and average annual incidence of hip fractures per 100,000, stratified by age and gender.

\begin{tabular}{lcccccc}
\hline Age group & \multicolumn{2}{c}{$\begin{array}{c}\text { Number of hip } \\
\text { fractures }\end{array}$} & \multicolumn{2}{c}{ Population in 2013 } & \multicolumn{2}{c}{ Average annual incidence rate [95\% CI] } \\
(years) & Women & Men & Women & Men & Women & Men \\
\hline $50-54$ & 1,752 & 2,300 & $2,156,672$ & $2,067,911$ & $27.1[25.8 ; 28.4]$ & $37.1[35.6 ; 38.6]$ \\
$55-59$ & 3,111 & 2,994 & $2,094,092$ & $1,965,394$ & $49.5[47.8 ; 51.3]$ & $50.8[49 ; 52.6]$ \\
$60-64$ & 4,812 & 3,779 & $2,071,333$ & $1,925,628$ & $77.4[75.3 ; 79.6]$ & $65.4[63.4 ; 67.5]$ \\
$65-69$ & 6,427 & 4,023 & $1,649,077$ & $1,496,495$ & $129.9[126.8 ; 133.1]$ & $89.6[86.9 ; 92.4]$ \\
$70-74$ & 8,876 & 4,324 & $1,266,545$ & $1,075,314$ & $233.6[228.8 ; 238.5]$ & $134[130.1 ; 138.1]$ \\
$75-79$ & 18,242 & 7,394 & $1,257,556$ & 936,511 & $483.5[476.6 ; 490.6]$ & $263.2[257.2 ; 269.2]$ \\
$80-84$ & 36,308 & 11,589 & $1,127,970$ & 706,912 & $1,073.0[1,062.0 ; 1,084.0]$ & $546.5[536.6 ; 556.5]$ \\
$85-89$ & 49,268 & 13,773 & 803,701 & 395,724 & $2,043.4[2,025.4 ; 2,061.5]$ & $1,160.2[1,140.9 ; 1,179.6]$ \\
$90-94$ & 36,079 & 8,670 & 367,011 & 136,739 & $3,276.8[3,243.2 ; 3,310.7]$ & $2,113.5[2,069.5 ; 2,158.2]$ \\
$95-99$ & 8,758 & 1,625 & 81,957 & 19,874 & $3,562.0[3,488.2 ; 3,637.0]$ & $2,725.5[2,596.2 ; 2,859.6]$ \\
$\geq 100$ & 1,949 & 275 & 18,741 & 3,327 & $3,466.6[3,316.2 ; 3,622.2]$ & $2,754.9[2,448.3 ; 3,089.9]$ \\
\hline
\end{tabular}

95\% CI: 95\% confidence interval 
Table 2: Relative risks (RRs) (95\% Bayesian credibility interval) of hip fractures by quartiles of French-EDI social deprivation index, GP and Nurse accessibility, and percentage of artificialized areas, according to Bayesian multivariate ecological regression, stratified by gender.

\begin{tabular}{|c|c|c|c|c|c|c|}
\hline & \multicolumn{3}{|c|}{ Women } & \multicolumn{3}{|c|}{ Men } \\
\hline & $\mathbf{R R}$ & $95 \%$ CI & Trend (p) & $\mathbf{R R}$ & $95 \%$ CI & Trend (p) \\
\hline \multicolumn{7}{|l|}{ French-EDI } \\
\hline Low, Q1, Reference & 1 & & & 1 & & \\
\hline Q2 & 0,995 & [0.9753-1.0151] & & 1,0429 & [1.0131-1.0725] & \\
\hline Q3 & 1,002 & [0.9812-1.0233] & & 1,0513 & [1.0192-1.0833] & \\
\hline Q4 & 1,004 & [0.9822-1.0253] & n.s. & 1,0811 & [1.0492-1.1152] & $<.0001$ \\
\hline \multicolumn{7}{|l|}{ GP accessibility } \\
\hline High, Q4, Reference & 1 & & & 1 & & \\
\hline Q3 & 1,008 & [0.9863-1.0302] & & 1,009 & [0.9775-1.0405] & \\
\hline Q2 & 1,015 & [0.9943-1.0361] & & 1,012 & [0.9837-1.0412] & \\
\hline Q1 & 1,031 & [1.0072-1.0544] & $<.05$ & 1,0141 & [0.982-1.0483] & $<.05$ \\
\hline \multicolumn{7}{|l|}{ Nurse accessibility } \\
\hline High, Q4, Reference & 1 & & & 1 & & \\
\hline Q3 & 0,991 & [0.9695-1.0131] & & 1 & [0.9704-1.0305] & \\
\hline Q2 & 1,021 & [0.9973-1.0463] & & 1,0071 & [0.9731-1.0412] & \\
\hline Q1 & 1,021 & [0.9945-1.0483] & n.s. & 1,0251 & [0.9873-1.0644] & $<.05$ \\
\hline \multicolumn{7}{|l|}{ \% Artificialized areas } \\
\hline High, Q4, Reference & 1 & & & 1 & & \\
\hline Q3 & 1,006 & [0.9841-1.0274] & & 1 & [0.9708-1.0302] & \\
\hline Q2 & 1,0471 & [1.0222-1.0725] & & 1,0393 & {$[1.005-1.0737]$} & \\
\hline Q1 & 1,0565 & [1.0274-1.0865] & $<.0001$ & 1,0431 & [1.0043-1.0834] & $<.01$ \\
\hline
\end{tabular}


Figure 1: Flow-chart of included hospital stays and patients

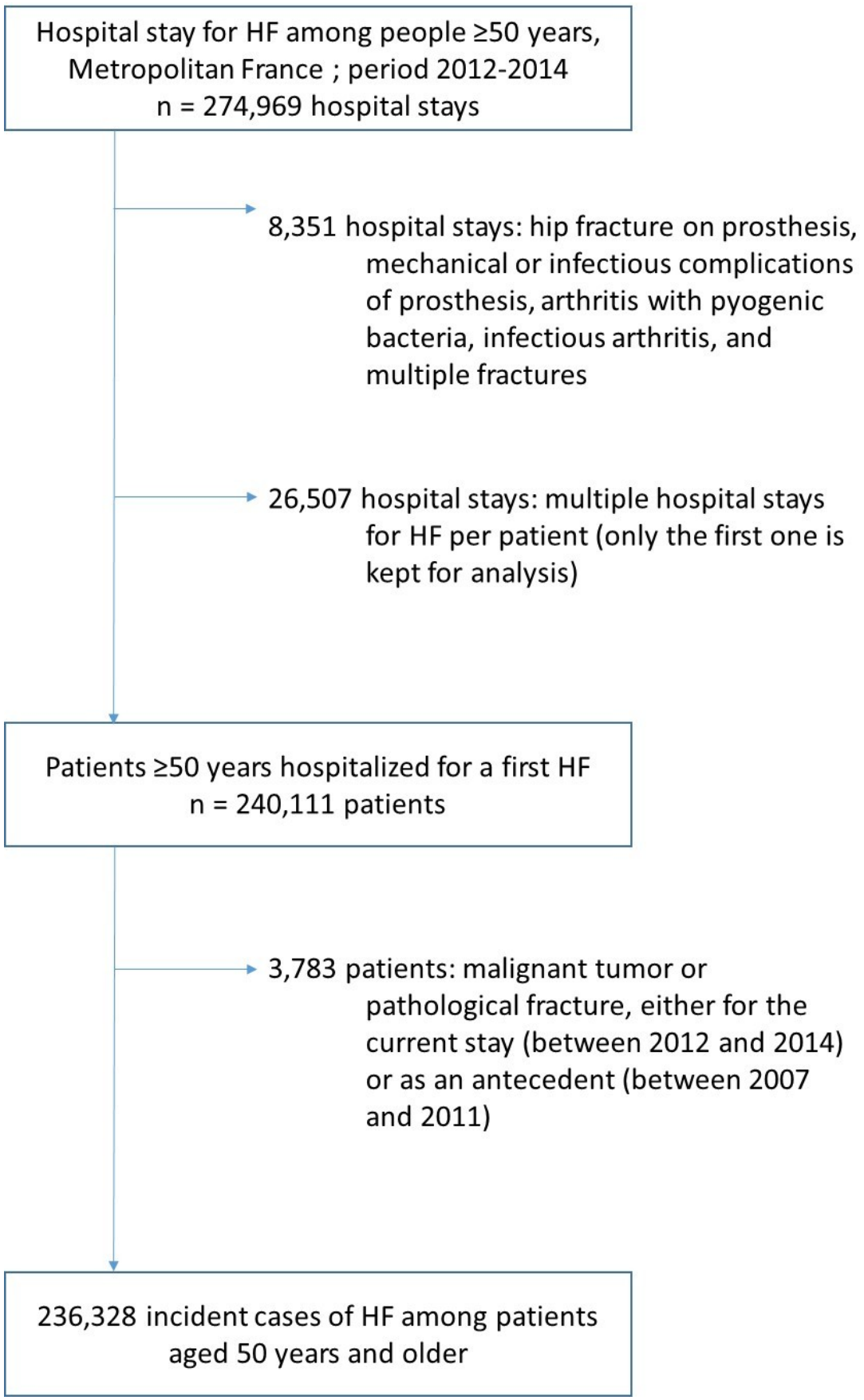


Figure 2: Smoothed age-and-gender standardized incidence ratios (SIRs) of hip fractures in metropolitan France, 2012-2014. 


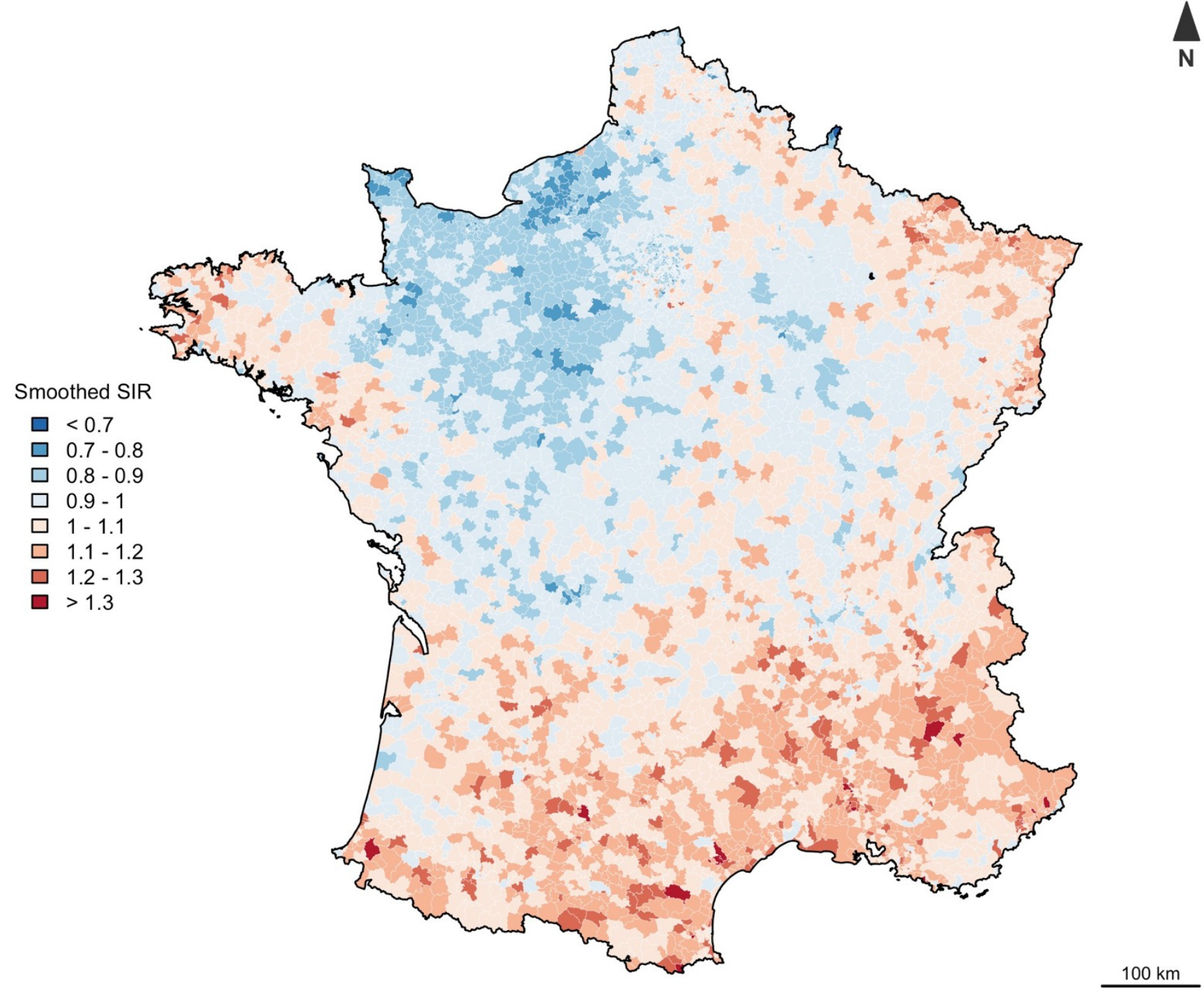

Figure 3. Relative risks (RRs) (95\% Bayesian credibility interval) of hip fractures by quartiles of French-EDI social deprivation index, GP and Nurse accessibility, and percentage of artificialized areas, according to Bayesian multivariate ecological regression. 


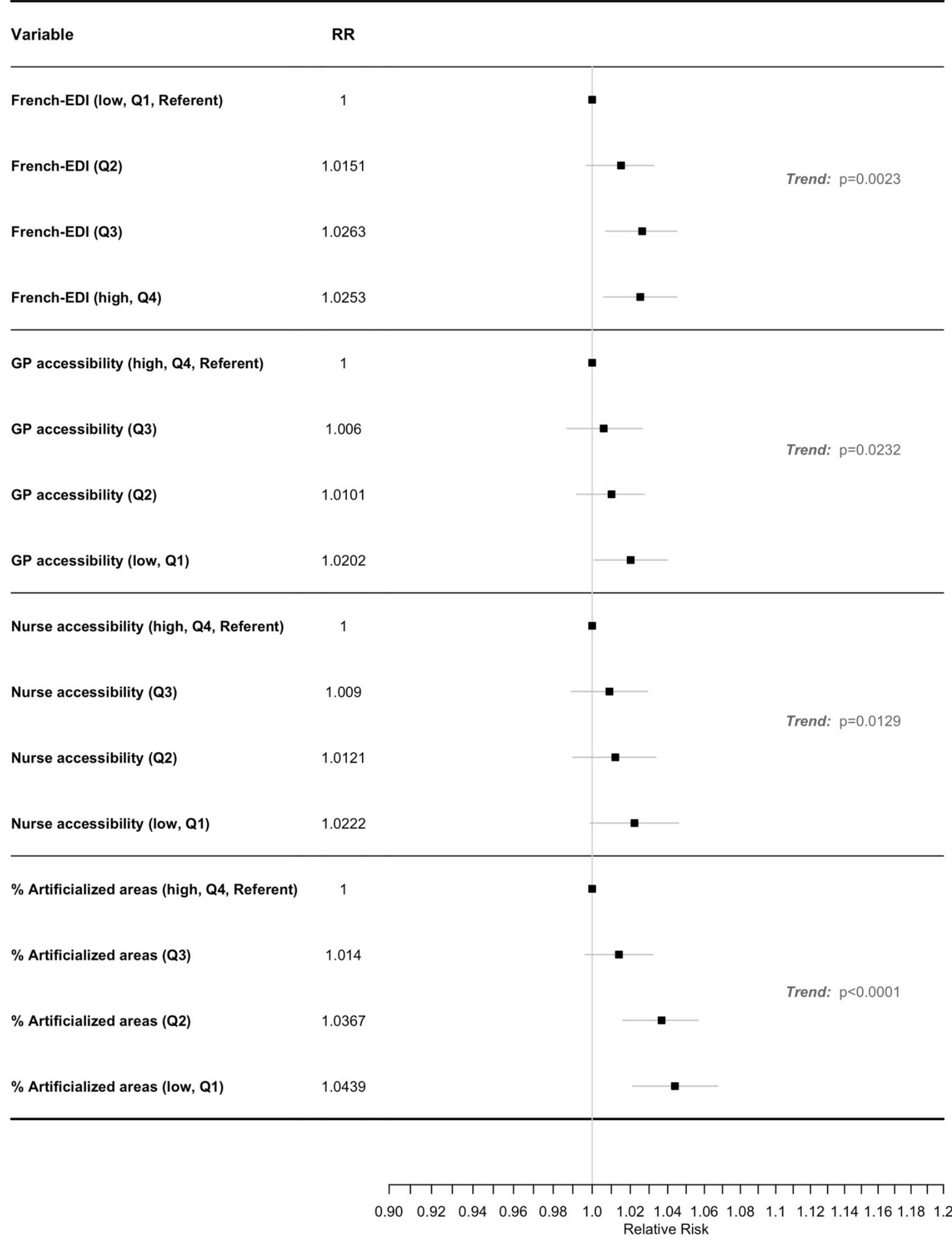

